\title{
Research on the shape distortion phenomenon in concave and convex flanging
}

\author{
Ling Yun Zhang ${ }^{1, a}$, Zuo Peng Fan ${ }^{2, b^{*}}$ \\ ${ }^{1,2}$ Key laboratory of fundamental science for national defence of aerouautical digital manufacturing \\ process, Shenyang Aerospace University, No.37 Daoyi South Avenue, Shenbei New Area, \\ Shenyang, China,110136 \\ azhangly79@163.com, ${ }^{\mathrm{b}} 125350814 @ q q . c o m$
}

Keywords: Concave and convex flanging; Finite element numerical simulation; Processing experiment; Shape distortion

Abstract:Concave and convex flanging is a relatively common form in sheet metal forming.However,since the sheet edge of flange parts is an unclosed free state.After curve flanging forming,there is a shape distortion phenomenon in parts. This shape distortion has a great impact on the quality of flange parts.In this paper, explore the shape distortion of curve flanging parts by finite element numerical simulation and experiment of flange forming process, and have an in-depth analysis the mechanism of shape distortion .

\section{Introduction}

The technology of curve flanging forming is widely used in automotive industry, aerospace and other industrial sectors, it refers to a plastic processing method that the blank along a straight or curved edge in the role of the mold, which fold the edge of blank into a vertical edge. There are three basic types: straight flanging, convex curve flanging(shrink flanging), concave curve flanging(stretch flanging),Fig.1. Straight flanging is similar to straight edge bent, and for convex curve flanging, it is easy to produce fold because the area of material deformation is mainly affected by circumferential compression stress. The area of material deformation of concave curve flanging is mainly affected by tensile stress, and flanging will produce fracture when the tensile stress exceeds a certain limit.On the other hand,since the side edge of deformation zone in curve flanging is not a closed area,it will be affected by boundary conditions,so after forming, the height of vertical edge of convex curve flanging is lower than intermediate vertical edge, and the end line of vertical side is outwardly incline.And the height of vertical edge of concave curve flanging is higher than intermediate vertical edge, the end line of vertical side is inwardly incline.

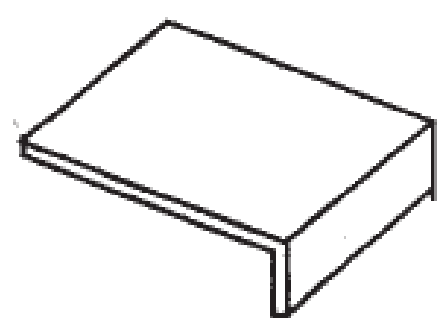

(a) Straight flanging

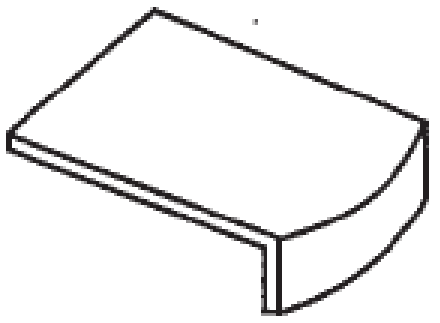

(b) Convex curve flanging

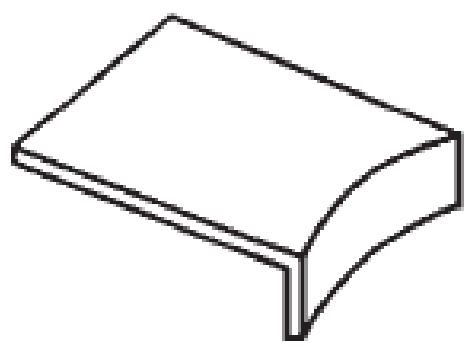

(c) Concave curve flanging

Fig.1 Different flange types

\section{Shape distortion phenomenon and analysis of mechanism in convex and concave flanging}

For the convex and concave flanging, Wang C.T. establish a mathematical model of stress and strain[1-2]. Nader Asnafi carried out a detail analysis of stress and strain in stretch and shrink flanging[3].Ping Hu establish a mathematical model for stretch/shrink flanging is developed based on the total strain theory and membrane assumption[4]. Now we ignored the stress on thickness 
direction. So establish a simplified mathematical model of convex curve flanging,Fig.2. Deformed area of sheet metal in convex flanging is ABCD.

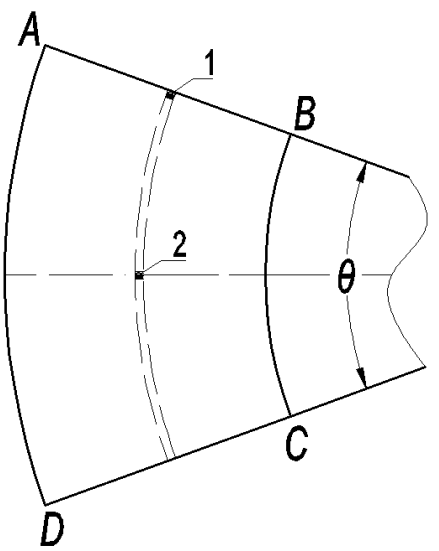

Fig.2 Simplified mathematical model of convex curve flanging

The circumferential angle of the sector deformation area is $\theta$ On the edge of the sector region ,AB and $\mathrm{CD}$, circumferential stress is zero, $\sigma_{\theta}=0$. Take small unit 1 and unit 2 to stress analysis,Fig. $3,\left(\sigma_{\theta 1}=0, \sigma_{r 1}>0, \sigma_{\theta 2}<0, \sigma_{r 2}>0\right)$
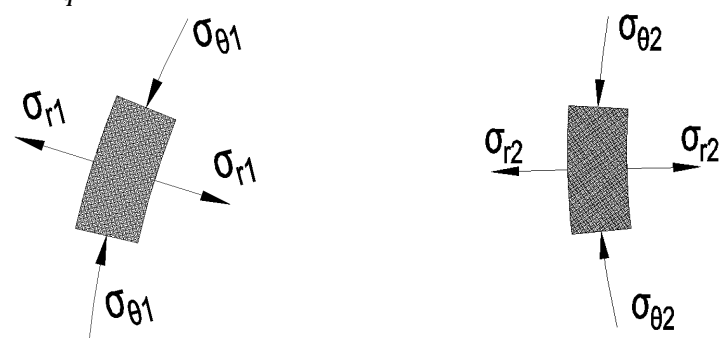

Fig. 3 Stress analysis of small unit 1 and unit2

So we can see that on the process of convex curve deformation,circumferential,the stress and strain distribution are not uniform. The convex curve flanging will be similar to cylindrical shallow drawing if $\theta$ increases to 360 degrees, then, the circumferential strain and circumferential contraction of the small unit 1 and 2 are same. Since the side edge of the sector area is free state,the shrinkage of edge is less than the middle position when the sheet deformation, it lead to the height of vertical edge is lower than intermediate vertical edge in the convex curve flanging, and the end line of vertical side is outwardly.

And for concave curve flanging, establish a simplified mathematical model of concave curve flanging,Fig.4. It is same to the convex curve flanging, the deformed area of sheet metal in caoncave flanging is $\mathrm{A}^{\prime} \mathrm{B}$ 'CD'.

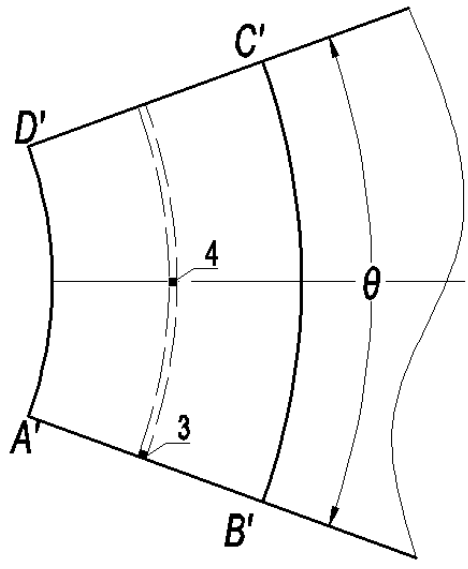

Fig.4 Simplified mathematical model of concave curve flanging

Take small unit 3 and unit 4 to stress analysis,Fig.5, $\left(\sigma_{\theta 3}=0, \sigma_{r 3}>0, \sigma_{\theta 4}>0, \sigma_{r 4}>0\right)$. So, the circumferential stress and strain distribution are not uniform in the deformation process of concave curve. Circumferential strain of small unit 3 and 4 are same when $\theta$ is 360 degrees, that is, the round hole bend. It is because of the side edge of the sector area is free state, the elongation indicator of edge 
is less than the middle position when the sheet deformation,so it will lead to the height of vertical edge of concave curve flanging is higher than intermediate vertical edge, and the end line of vertical side is inwardly incline.
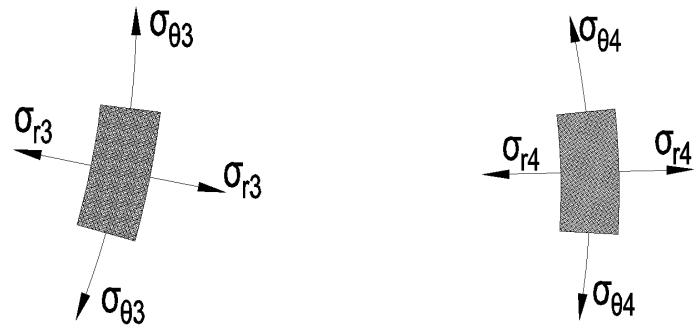

Fig.5 Stress analysis of small unit 3 and unit 4

\section{Numerical simulation and experiment of flange forming process}

In order to verify the shape distortion of concave and convex flanging,we did a large number of finite element simulation by software(Abaqus) and forning process experiment. Consider a blank shape as shown in Fig.6. The material of sheet is $2 A 12-O$,its thickness is $1 \mathrm{~mm}, R_{1}=38 \mathrm{~mm}, R_{2}=92 \mathrm{~mm}$. The finite element numerical simulation model as shown in Fig.7.And mechanical properties of materials as shown in table1.
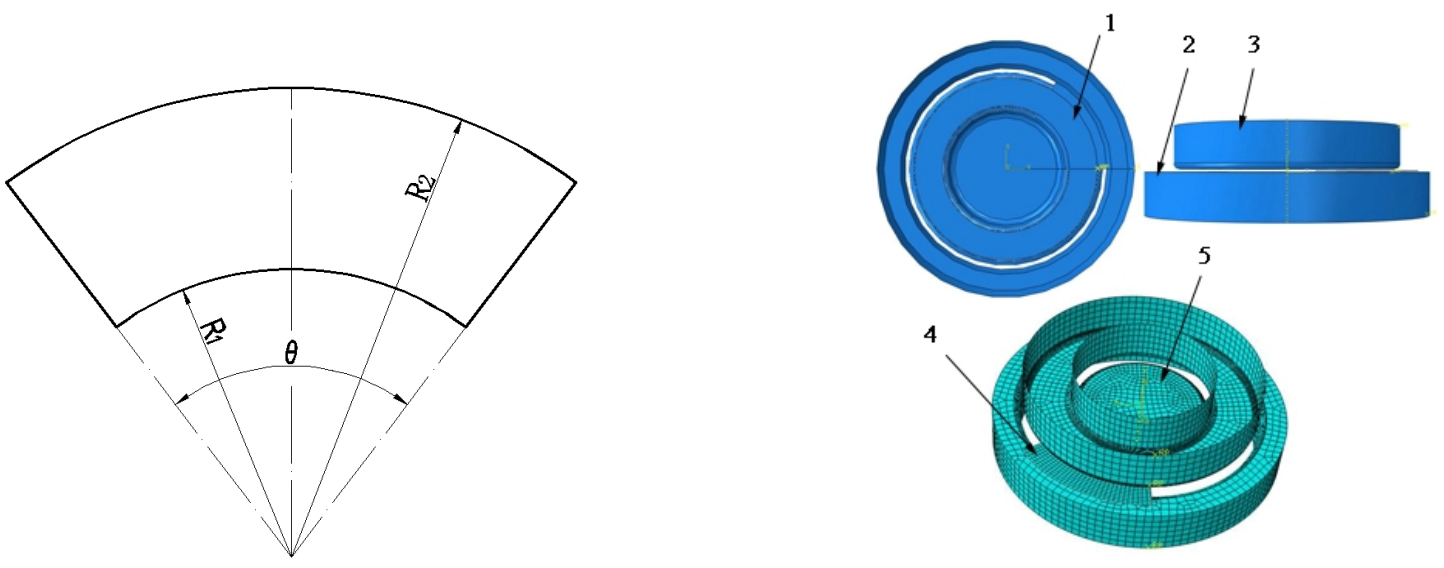

1-Blank holder,2-Punch of convex curve flanging,3-Die,4-Blank

5- Punch of concave curve

Fig.6 Blank shape

Fig.7 Model of finite element numerical simulation

Table1. The mechanical properties of materials

\begin{tabular}{|c|c|c|c|c|}
\hline material & poisson ratio & tensile strength/MPa & yield strength/MPa & elongation/\% \\
\hline 2A12-O & 0.33 & 185 & 75 & $\geq 0.20$ \\
\hline
\end{tabular}

The results of finite element numerical simulation and experiment as shown in Fig.8(a) and Fig.8(b).
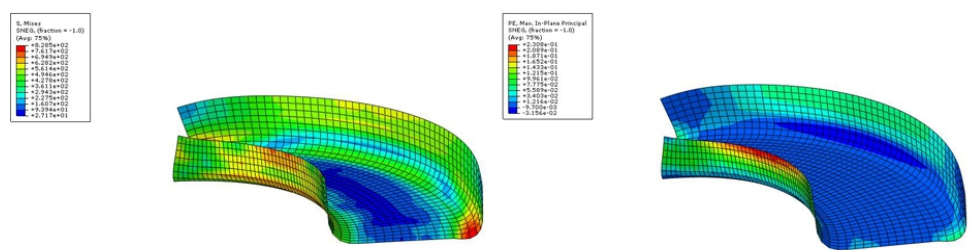

Fig.8(a) The results of finite element numerical simulation 


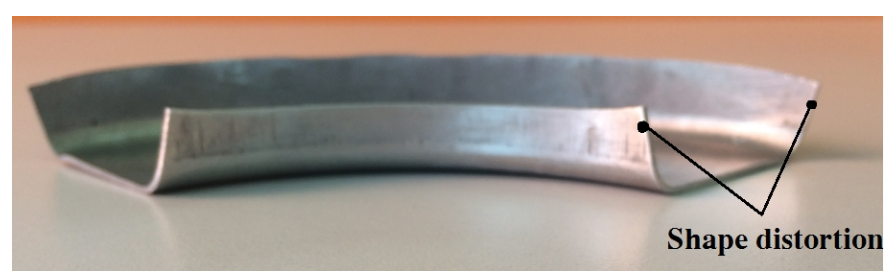

Fig.8(b) Experimental part

Measured the height of vertical side and sheet thickness values after forming are shown in Table 2 and Table 3.

Table 2. Vertical edge height of experimental part

\begin{tabular}{|c|c|c|c|c|c|c|}
\hline \multirow{2}{*}{$\begin{array}{c}\text { No } \\
\cdot\end{array}$} & \multicolumn{3}{|c|}{ The vertical height of the convex curve } & \multicolumn{3}{c|}{ The vertical height of the concave curve } \\
flanging & Left edge & $\begin{array}{c}\text { Center of } \\
\text { symmetry }\end{array}$ & Right edge & Left edge & $\begin{array}{c}\text { Center of } \\
\text { symmetry }\end{array}$ & Right edge \\
\cline { 2 - 7 } & $12.01 \mathrm{~mm}$ & $13.94 \mathrm{~mm}$ & $11.99 \mathrm{~mm}$ & $11.60 \mathrm{~mm}$ & $10.38 \mathrm{~mm}$ & $11.53 \mathrm{~mm}$ \\
\hline 2 & $12.00 \mathrm{~mm}$ & $14.01 \mathrm{~mm}$ & $12.03 \mathrm{~mm}$ & $11.62 \mathrm{~mm}$ & $10.40 \mathrm{~mm}$ & $11.58 \mathrm{~mm}$ \\
\hline 3 & $11.98 \mathrm{~mm}$ & $13.99 \mathrm{~mm}$ & $11.97 \mathrm{~mm}$ & $11.57 \mathrm{~mm}$ & $10.43 \mathrm{~mm}$ & $11.55 \mathrm{~mm}$ \\
\hline
\end{tabular}

Table 3. The sheet thickness of sheet after forming (The initial thickness of the blank is $1 \mathrm{~mm}$ )

\begin{tabular}{|c|c|c|c|}
\hline No. & $\begin{array}{c}\text { The thickness of side edges } \\
\text { after convex curve } \\
\text { flanging(average value) }\end{array}$ & $\begin{array}{c}\text { The thickness of } \\
\text { web(average value) }\end{array}$ & $\begin{array}{c}\text { The thickness of side edges } \\
\text { after convex curve } \\
\text { flanging(average value) }\end{array}$ \\
\hline 1 & $1.01 \mathrm{~mm}$ & $0.99 \mathrm{~mm}$ & $0.98 \mathrm{~mm}$ \\
\hline 2 & $0.99 \mathrm{~mm}$ & $0.98 \mathrm{~mm}$ & $0.96 \mathrm{~mm}$ \\
\hline 3 & $0.98 \mathrm{~mm}$ & $0.97 \mathrm{~mm}$ & $0.96 \mathrm{~mm}$ \\
\hline
\end{tabular}

\section{Conclusion}

Above for an in-depth analysis the mechanism of shape distortion in concave and convex flanging, according to the table 2 , the thickness of sheet metal is essentially unchanged after curve flanging.So we suppose that the thickness strain is zero is feasible.In curve flanging, stress and strain distribution is uneven. The result of finite element numerical simulation and measured the height of vertical edge of parts in concave and convex flanging, more intuitive reflects the shape distortion phenomenon. These achievements can lay the foundation for the correction of blank.

\section{References}

[1].Chuan-tao Wang,Gary Kinzel,Taylan Altan.Failure and wrinkling criteria and mathermatical modeling of shrink and stretch flanging operations in sheet-metal forming,J . Journal of Materials processing Technology.53 (1995) 759-780.

[2]. Wang C.T.etc. Investigation of shrink Flanging Prediction of Wrinkling and Experimental Verification.SAE Paper (1974) No940939 .

[3] .Nader Asnafi. On stretch and shrink flanging of sheet aluminium by build forming ,J . Journal of Materials Processing Technology.96 (1999) 198-214 .

[4]. .Ping Hu. Analytical models of sheet metal stamping ,J,Theoretical and Applied Mechanics.(20010) (6).803811 .

[5]. Xiao Li. Principle of metal plastic forming, first ed,Machinery Industry Press,Beijing,2004. 